See Article page e59.

\section{Commentary: Change the temperature before we have to}

Yuka Kadomatsu, MD, and

Toyofumi Fengshi Chen-Yoshikawa, MD, PhD

Due to potential lung injuries such as microthrombus and vascular insufficiency, more than $80 \%$ of donor grafts are unsuitable for transplantation. ${ }^{1}$ To alleviate the chronic shortage of organs, the use of ex vivo lung perfusion (EVLP) has been highlighted. EVLP plays a vital role in assessing donor lung function and even potentially recovering marginal-quality grafts. Whether the use of EVLP improves the outcome of lung transplantation remains controversial, and the settings need to be urgently optimized. ${ }^{2}$ In this issue of the Journal, Gloria and colleagues ${ }^{3}$ reported that subnormothermic EVLP attenuated graft inflammation in a rat transplant model.

Although in an animal model, graft perfusion at a lower temperature $\left(4^{\circ} \mathrm{C}-10^{\circ} \mathrm{C}\right)$ is useful for graft protection, EVLP has been performed mainly under normothermic conditions in the clinical setting. ${ }^{4}$ The authors focused on this point and hypothesized that a lower EVLP temperature $\left(25^{\circ} \mathrm{C}\right)$ might have some advantages in reducing allograft inflammation. The concept of subnormothermic perfusion has been tested mainly in the kidney and liver, whereas its preventive effect on anti-inflammatory changes of grafts has hardly been investigated in the lungs. In this study, several biomarkers, such as tumor necrosis factor alpha (TNF- $\alpha$ ) and high-mobility group box1 (HMGB1). were evaluated. A greater level of HMGB1 in EVLP is associated with primary graft dysfunction after human lung transplantation. ${ }^{5}$ Gloria and colleagues confirmed that the rate of elevation of HMGB1 was diminished at lower temperatures. The authors also showed that the level of circulating TNF- $\alpha$ was significantly lower at $25^{\circ} \mathrm{C}$ and $30^{\circ} \mathrm{C}$ than at $37^{\circ} \mathrm{C}$. They successfully showed the possibility of advantages of antiinflammatory reaction in subnormothermic EVLP.

\footnotetext{
From the Department of Thoracic Surgery, Nagoya University Graduate School of Medicine, Nagoya, Japan.

Disclosures: The authors reported no conflicts of interest.

The Journal policy requires editors and reviewers to disclose conflicts of interest and to decline handling or reviewing manuscripts for which they may have a conflict of interest. The editors and reviewers of this article have no conflicts of interest.

Received for publication Jan 21, 2021; revisions received Jan 21, 2021; accepted for publication Jan 21, 2021; available ahead of print Jan 30, 2021.

Address for reprints: Toyofumi Fengshi Chen-Yoshikawa, MD, PhD, Department of Thoracic Surgery, Graduate School of Medicine, Nagoya University, 65 Tsurumaicho, Showa-ku, Nagoya, Japan (E-mail: tyoshikawa@med.nagoya-u.ac.jp).

J Thorac Cardiovasc Surg 2022;164:e71-2

$0022-5223 / \$ 36.00$

Copyright (C) 2021 by The American Association for Thoracic Surgery

https://doi.org/10.1016/j.jtcvs.2021.01.083
}

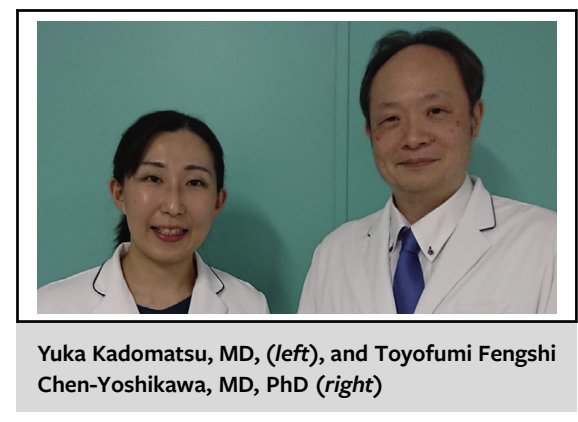

This study has several limitations. As the authors mentioned, post-transplantation lung function was evaluated only for a short time period, and the mid- to long-term effect of this setting, "subnormothermic," remains unclear. In the setting of this study, cold static storage showed the best lung preservation, although the preservation time was short compared with clinical lung transplantation. Furthermore, injured graft lungs were not used in this study, so the results would change using damaged grafts. The experiments were performed in a rat model, and some results in this study might have discrepancies in a clinical human EVLP situation. For example, the levels of TNF- $\alpha$ and HMGB1 were the lowest in the control group (no EVLP group), and the normothermic group showed a continuous increase in TNF- $\alpha$. This discrepancy has not been reasonably explained, but differences in settings need to be considered when interpreting the results of this study.

We congratulate Gloria and colleagues for their efforts to improve the settings of EVLP for a better outcome after lung transplantation. Future studies in a large animal model may establish the ideal and robust settings of EVLP for better graft outcomes after lung transplantation and lead to the extended use of lung grafts and better post-transplantation outcomes.

\title{
References
}

1. Cypel M, Yeung JC, Liu M, Anraku M, Chen F, Karolak W, et al. Normothermic ex vivo lung perfusion in clinical lung transplantation. $N$ Engl J Med. 2011;364: 1431-40. 
2. Chakos A, Ferret P, Muston B, Yan TD, Tian DH. Ex-vivo lung perfusion versus standard protocol lung transplantation-mid-term survival and meta-analysis. Ann Cardiothorac Surg. 2020;9:1-9.

3. Gloria JN, Yerxa J, Kesseli SJ, Davis RP, Samoylova ML, Barbas AS, et al. Subnormothermic ex vivo lung perfusion attenuates graft inflammation in a rat transplant model. J Thorac Cardiovasc Surg. 2022; 164:e59-70.
4. Nakajima D, Chen F, Yamada T, Sakamoto J, Osumi A, Fujinaga T, et al. Hypothermic machine perfusion ameliorates ischemia-reperfusion injury in rat lungs from non-heart-beating donors. Transplantation. 2011;92:858-63.

5. Hashimoto K, Cypel M, Juvet S, Saito T, Zamel R, Machuca TN, et al. Higher M30 and high mobility group box 1 protein levels in ex vivo lung perfusate are associated with primary graft dysfunction after human lung transplantation. $J$ Heart Lung Transplant. 2017;17:1870-3.
See Article page e59.

\section{Commentary: Colder may be better in ex vivo lung preservation}

\author{
Stephanie H. Chang, MD
}

Ex vivo lung perfusion (EVLP) has emerged over the last decade as a method of expanding the donor pool for lung transplantation. ${ }^{1}$ The current clinical use of EVLP occurs with normothermic perfusion of the donor allograft, which has resulted in similar short-term ${ }^{1}$ and long-term ${ }^{2}$ outcomes compared with non-EVLP lung transplants. However, other solid organs have used hypothermic machine perfusion with good outcomes, ${ }^{3}$ leading to a current clinical trial to determine whether normothermic or hypothermic machine perfusion results in improved outcomes for liver transplantation.

To determine whether subnormothermic perfusion for EVLP can be beneficial, the authors used a rat model to evaluate damage-associated molecular patterns (DAMPs) at different temperatures while on EVLP. ${ }^{4}$ Clinical studies have previously demonstrated that increased ischemiareperfusion injury, as measured by increased cell death signals, in EVLP perfusate has been associated with grade 3 primary graft dysfunction (PGD), as well as higher mortality. ${ }^{5}$ Thus, the authors evaluated cell death signals and DAMPs in the perfusate at normothermic $\left(37^{\circ} \mathrm{C}\right)$ and subnormothermic $\left(30^{\circ} \mathrm{C}\right.$ and $\left.25^{\circ} \mathrm{C}\right)$ temperatures. The $25^{\circ} \mathrm{C}$ EVLP was associated with a lower increase in certain

From the Department of Cardiothoracic Surgery, New York University Langone Health, New York, NY.

Disclosures: The author reported no conflicts of interest.

The Journal policy requires editors and reviewers to disclose conflicts of interest and to decline handling or reviewing manuscripts for which they may have a conflict of interest. The editors and reviewers of this article have no conflicts of interest.

Received for publication Feb 1, 2021; revisions received Feb 1, 2021; accepted for publication Feb 3, 2021; available ahead of print Feb 9, 2021.

Address for reprints: Stephanie H. Chang, MD, Division of Thoracic Surgery, Department of Cardiothoracic Surgery, New York University Langone Health, 530 First Ave, Suite 9V, New York, NY 10016 (E-mail: stephanie.chang@nyulangone.org). J Thorac Cardiovasc Surg 2022;164:e72-3

$0022-5223 / \$ 36.00$

Copyright (C) 2021 by The American Association for Thoracic Surgery

https://doi.org/10.1016/j.jtcvs.2021.02.006
Check for updates

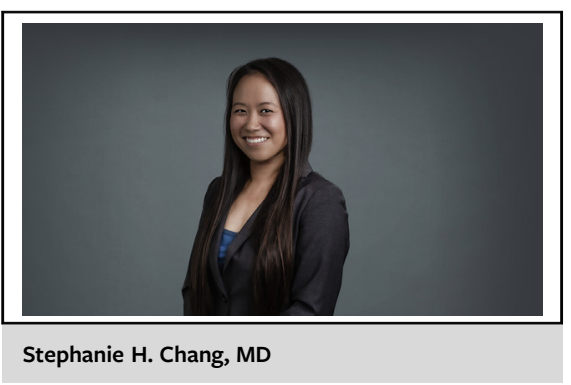

CENTRAL MESSAGE

Ex vivo lung perfusion (EVLP) at

$25^{\circ} \mathrm{C}$ appears to be associated

with decreased histologic injury

and cell death signals compared

to normothermic EVLP in an

animal model. Further studies are

needed to evaluate clinical

efficacy.

cytokines and DAMPs compared with normothermic EVLP, suggesting decreased inflammation with subnormothermic EVLP. Transplanted lungs from the 3 EVLP groups $\left(37^{\circ} \mathrm{C}, 30^{\circ} \mathrm{C}\right.$, and $\left.25^{\circ} \mathrm{C}\right)$ and from static cold storage (SCS) were also compared at 2 hours posttransplantation. Although there was no significant difference in the ratio of arterial oxygen concentration to the fraction of inspired oxygen $(\mathrm{P} / \mathrm{F}$ ratio), there was a greater histologic injury in the $37^{\circ} \mathrm{C}$ and $30^{\circ} \mathrm{C}$ groups compared with SCS, with no difference between $25^{\circ} \mathrm{C}$ and SCS. Although this rat model demonstrates the potential decreased inflammation and posttransplantation graft injury in subnormothermic EVLP, the posttransplantation measurement of DAMPs and cytokines still favor SCS even over subnormothermic EVLP.

The results from this article are overall promising in demonstrating possible decreased injury in subnormothermic EVLP. However, there are additional models that 